REFERENCES:

[1] Kroot, E.J., et al., Chronic comorbidity in patients with early rheumatoid arthritis: a descriptive study. J Rheumatol, 2001. 28(7): p. 1511-7.

[2] Castaneda, S., et al., Additional proposals to reduce comorbidity in patients with chronic inflammatory rheumatic diseases: comment on 'Points to consider for reporting, screening for and preventing selected comorbidities in chronic inflammatory rheumatic diseases in daily practice: a EULAR initiative' by Baillet et al. Ann Rheum Dis, 2016. 75(8): p. e55.

Disclosure of Interests: None declared

DOI: 10.1136/annrheumdis-2021-eular.2094

\section{FILGOTINIB DEMONSTRATES CLINICAL EFFICACY IN RHEUMATOID ARTHRITIS INDEPENDENT OF SMOKING STATUS: A POST-HOC SUBGROUP ANALYSIS OF THREE PHASE 3 CLINICAL TRIALS}

P. Emery ${ }^{1}$, B. Downie ${ }^{2}$, J. Liu ${ }^{2}$, R. Hawtin ${ }^{2}$, J. R. Curtis ${ }^{3}$, G. R. Burmester ${ }^{4}$. ${ }^{1}$ University of Leeds, School of Medicine, Leeds, United Kingdom; ${ }^{2}$ Gilead Sciences, Inc., Foster City, United States of America; ${ }^{3}$ University of Alabama at Birmingham, Division of Clinical Immunology and Rheumatology, Birmingham, United States of America; ${ }^{4}$ Charité Universitätsmedizin Berlin, Department of Rheumatology and Clinical Immunology, Berlin, Germany

Background: Filgotinib (FIL), an oral janus kinase 1 (JAK1) inhibitor, has been evaluated in three phase 3 clinical studies (FINCH 1-3) in adults with moderately-to-severely active rheumatoid arthritis (RA). Patients with RA who currently smoke (a predisposing factor for RA) have been reported to be less likely to respond to anti-TNF $\alpha$ treatment and more likely to discontinue or switch treatment. ${ }^{1,2,3}$ However, the impact of smoking on JAKi efficacy in RA patients is unknown.

Objectives: A post-hoc sub-group analysis of FINCH patient (pt) data was performed in order to identify associations with smoking status.

Methods: Data from 3452 RA pts participating in the FINCH3 (MTXnaïve; NCT02886728), FINCH1 (MTX-IR; NCT02889796), or FINCH2 (bDMARD-IR; NCT02873936) clinical trials were included for analysis of clinical response at weeks 12 and 24. Logistic regression models were fitted to assess the effects of smoking status on categorical clinical endpoints (ACR20/50/70, CDAI $\leq 10$, DAS28(CRP) $\leq 3.2$ or $<2.6$ ). Adjustments were made for covariates selected based on previously published work ${ }^{1}$ and listed in the Figure 1 caption. No adjustments of $p$-values were made for multiple testing.

Results: In the MTX-IR population (FINCH1), current (12\% of enrolled patients) and former (13\%) smokers treated with ADA+MTX had a lower week 12 ACR50 response rate compared to non-smokers (25\% and $28 \%$ vs. $39 \%$, nominal $p=0.095$ and $p=0.21$, respectively). In contrast, the ACR 50 response at week 12 in FIL+MTX treated pts showed no association with smoking status. Former smokers had higher response rates than non-smokers in the MTX-IR (FINCH1) and MTX naïve (FINCH3) populations (Table 1). Direct comparison between non-smoking pts in the MTX-IR FIL200+MTX-arm and ADA+MTX-arm showed no significant difference in ACR50 response rate $(46 \%$ vs. $39 \%, p=0.08)$. In contrast, former and current smokers showed significantly better week 12 ACR50 response rates under FIL200+MTX treatment compared to ADA+MTX patients (former smoker: $62 \%$ vs. $28 \%, p=0.0017$, current smoker: $50 \%$ vs. $25 \%, p=0.016$, Figure 1. Similar observations were made at both weeks 12 and 24 for other clinical endpoints, including ACR20/50/70, DAS28(CRP) $<2.6$ or $\leq 3.2$, and $\mathrm{CDAl} \leq 10$ response criteria.

Table 1. Difference in adjusted ACR50 response rate compared to non-smokers for FINCH1/2/3.

\begin{tabular}{llccc}
\hline & & PBO+MTX & FIL100+MTX & FIL200+MTX \\
\hline FINCH1 & Current & $-1 \%$ & $+2.4 \%$ & $+3.3 \%$ \\
& Former & $-6 \%$ & $+12 \%$ & $+16 \%\left(^{\star}\right)$ \\
FINCH2 $^{\dagger}$ & Current & $0 \%$ & $+13 \%$ & $-9 \%$ \\
& Former & $+9 \%$ & $-7 \%$ & $+4 \%$ \\
FINCH3 & Current & $0 \%$ & $+1 \%$ & $+4 \%$ \\
& Former & $+4 \%$ & $+20 \%\left(^{\star}\right)$ & $+17 \%\left(^{\star}\right)$
\end{tabular}

ACR50 response rate based on fully adjusted logistic regression model. ${ }^{\dagger}$ : $\mathrm{FINCH} 2$ patients received either MTX or csDMARD. ${ }^{\ddagger} \mathrm{FINCH} 3$ had active comparator arm of MTX together with PBO to maintain blind. ${ }^{*}: p<0.05,{ }^{* *}: p<0.01,{ }^{* \star *}: p<0.001$
FINCH1: Week 12 ACR50 Responder Response rate by smoke status

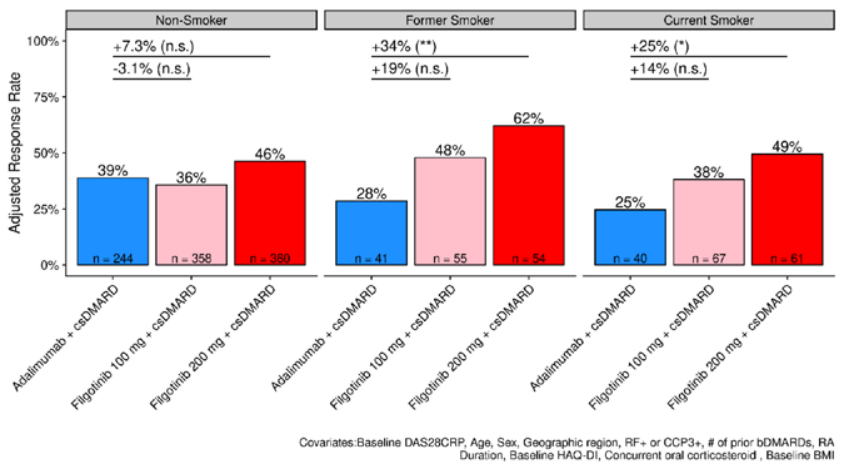

Figure 1. FINCH1 adjusted Week 12 ACR50 response rate stratified by smoking status. ACR50 response rate based on fully adjusted logistic regression model. *: $p<0.05 ;{ }^{* *}$ : $p<0.01$ ${ }^{\star * \star}: p<0.001$. Former and current smokers that received FIL200mg + MTX showed a higher response rate compared to similar ADA+MTX patients.

Conclusion: This exploratory analysis showed that current and former smokers with RA who received ADA+MTX trended toward a lower response rate compared to non-smokers. In contrast, FIL+MTX was found to be similarly efficacious independent of smoking status within both the MTX-IR and MTX-naïve RA populations. Current or former smokers were more likely to respond to FIL200mg + MTX compared to ADA+MTX across a range of endpoints. Given the small number of current and former smokers enrolled in these studies, further studies of the efficacy of JAK inhibitors and the mechanism of reduced response to antiTNFs in patients with a history of smoking are warranted.

\section{REFERENCES:}

[1] Hyrich KL. Rheumatology 2006;45:1558-1565; 2. Canhao H. Rheumatology 2012;51:2020-2026; 3. McCulley CB. Clin Exp Rheumatol 2019;28(37):422-428

Disclosure of Interests: Paul Emery Consultant of: Pfizer, Abbvie, Amgen, MSD Roche, Sanofi, BMS, Novartis, Lilly, Gilead, Samsung, Celltrion, Grant/research support from: Abbvie, BMS, Samsung, Bryan Downie Shareholder of: Gilead, Employee of: Gilead, Jinfeng Liu Shareholder of: Gilead, Roche, Employee of: Gilead, Rachael Hawtin Shareholder of: Gilead, Employee of: Gilead, Jeffrey R. Curtis Consultant of: Abbvie, Amgen, BMS, Corrona, Eli Lilly, Jannsen, Myriad, Pfizer, Regeneron, Roche, and UCB, Grant/research support from: Abbvie, Amgen, BMS, Corrona, Eli Lilly, Jannsen, Myriad, Pfizer, Regeneron, Roche, and UCB, Gerd Rüdiger Burmester Speakers bureau: Abbvie, Gilead, Lilly, Pfizer, Consultant of: Abbvie, Gilead, Lilly, Pfizer

DOI: 10.1136/annrheumdis-2021-eular.2128

\section{\begin{tabular}{|l|}
\hline POS0537 TRENDS AND PREDICTORS OF INPATIENT \\
\hline
\end{tabular} MORTALITY IN PATIENTS WITH CLOSTRIDIODES DIFFICILE INFECTION AMONG THOSE WITH AND WITHOUT RHEUMATOID ARTHRITIS: A NATIONWIDE ANALYSIS}

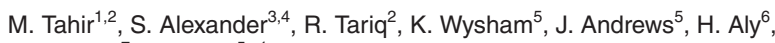
S. Khanna ${ }^{7}$, N. Singh ${ }^{5} .{ }^{1}$ Rochester General Hospital, Internal Medicine, Rochester, United States of America; ${ }^{2} 1425$ Portland Ave, Internal Medicine, Rochester, United States of America; ${ }^{3}$ University of Connecticut, Internal Medicine, Storrs, United States of America; ${ }^{4} 263$ Farmington Ave, Internal Medicine, Farmington, United States of America; ${ }^{5} 1959$ NE Pacific St, Internal Medicine, Seattle, United States of America; ${ }^{6} 740$ S Limestone, Internal Medicine, Lexington, United States of America; ${ }^{7} 200$ 1st St SW, Internal Medicine, Rochester, United States of America

Background: People with rheumatoid arthritis (RA) have a higher risk of serious infections. The most common nosocomial infection in the United States (US) is Clostridioides difficile infection (CDI) and yet, little is known regarding the impact of comorbid RA on outcomes in persons hospitalized with CDI.

Objectives: To evaluate the trends over time and predictors of inpatient mortality in hospitalized patients with CDI comparing those with and without RA.

Methods: We used the National Inpatient Sample (NIS) database, the largest available all-payer database of inpatient hospitalizations in the US. Patients aged 